\title{
An Engineering Curriculum to Meet the Challenges of the Present Decade
}

\author{
${ }^{1}$ K. Jaya Sankar, ${ }^{2}$ M. Satyam, ${ }^{3}$ P.A. Govindacharyulu, ${ }^{4}$ E. Sreenivasa Rao \\ 1,2,3,4 Department of ECE, Vasavi College of Engineering (Autonomous), Ibrahimbagh, Hyderabad -500031, Telangana, India. \\ 1hodece@staff.vce.ac.in \\ ${ }^{2}$ satyam_mandavilli@yahoo.com \\ 33ovindacharyulu@gmail.com \\ e.sreenivasarao@staff.vce.ac.in
}

\begin{abstract}
The challenges that the engineering education faces today are (1) Lack of demand forecasting of requirement of different types of engineering, say after a period of 4 years and beyond; (2) Lack of proper training in required skills for direct placement of the students and (3) The number of graduates that may be required for different industries, research labs, educational institutes etc. To meet these challenges, to some extent, we propose a curriculum through which the engineering student is trained in engineering fundamentals, broad specialization and product realization with the participation of the industries (in teaching activities) the forecasting period gets reduced to almost 2 years or less which helps in arriving at reasonable estimates of types of engineers, the number of each type of engineers. Further the curriculum enables the students to be directly employed or with minimum further training and skill up-gradation.
\end{abstract}

K. Jaya Sankar

Department of ECE, Vasavi College of Engineering (A), Ibrahimbagh, Hyderabad -500031, Telangana, India. hodece@staff.vce.ac.in

\section{Introduction}

As the science and engineering are evolving, newer devices, gadgets and systems are being invented. These devices and gadgets help humanity to have better living, better medical attention, faster communication, faster commuting and variety in entertainment. All these are made possible by teams of engineers who have different talents and knowledge bases. The knowledge base of each student is different from that of another student with varying degrees of overlaps and also with some exclusive features. It is this characteristic which enables the students to work together as teams, to develop better and newer gadgets and devices impacting the society and its environment. In view of this evolutionary process it is mandatory to develop curricula, for training engineers, which provide these students with some common base knowledge and also provide opportunities for individual to show his / her talent and exclusiveness further. The trained engineers should be able to fit into the new frame of progress and development, which is reflected through the placement, after institutional training. In view of this we propose a pattern of engineering curriculum and its implementation, which is likely to meet these requirements.

\section{Present Method of Engineering Training at Institution Level}

The engineering programs are available presently in our country at different levels. The first level of training consists of certificate training courses, which are generally specialised courses in technical skills and are available after SSLC or $10^{\text {th }}$ standard. They are mostly skill based, like carpentry, mechanics, electrical maintenance, shoe making and so on. Large number of such skilled people form the foundation for any development work. The second level of engineering training is normally offered by diploma courses. These courses cater to the need of different activities like civil construction, electrical machine design and wiring, maintenance of mechanical and electrical gadgets and so on. They are generally offered in various disciplines like civil, mechanical, electrical, electronics etc. These people get a little bit of 
understanding of the operation of the gadgets and design them and maintain them. There is the third level of engineering, at the end of which a bachelor degree is awarded to a person after successful completion of training and they are called, engineers.

These engineers form the foundation for the material prosperity of any country. They are the architects of new and more efficient and user friendly devices and gadgets. To meet this goal the students, who enter engineering institutions, after their $10+2$ programs (intermediate $/ 12^{\text {th }}$ standard) should be trained to apply their mind to the issues related to efficiency, reliability, improvement in performance etc of the devices, gadgets and structures which impact the society. To achieve this goal the training program (engineering curriculum) should be such that

1) The student acquires sufficient knowledge in areas like cause and effect analysis - (physics, chemistry), performance evaluation (mathematics, mathematical and analytical methods) and methods of realizing the structures, \& devices (Technology involving design techniques fabrication techniques, etc).

2) The student should be exposed or trained to apply his knowledge based thoughts to realize a device, gadget or a system. This calls for intensive laboratory program.

3) The student must be able to visualise a problem from, what he observes and formulate it and arrive at a methodology to solve it with what he has studied and his own ideas and demonstrate it.

4) There is a responsibility on the part of the institution and the government to generate manpower of a specific type and number which can be used by industry. This also benefits the students to get gainful employment.

5) This article looks at the curriculum that is practised at present and proposes a new curriculum that will meet all the above criteria.

\section{Present Structure of Engineering Curriculum}

Engineering courses are offered in different streams like civil, electrical, mechanical, electronics, computer science etc., and some courses like mechatronics, aeronautics etc., are offered only in very few institutions. Students are directly admitted into a particular stream and they are trained in that stream for 4 years after which they are awarded the degree in that particular discipline. The curriculum for each stream is prepared separately and the common courses are generally limited to basic courses in mathematics, physics and chemistry and some courses in humanities. With this type of program the students generally get placed in a few engineering industries and departments. The number of required people in any department varies from year to year (swings from very low to very high values) and as such a lot of students are left without jobs in some disciplines and there is scarcity of trained man power in other disciplines. This has become a very acute problem in engineering man power management. Further, there are complaints from employers saying that the students are not trained properly and the companies are forced to give these employees some sort of orientation, make up training etc., before they can be employed gainfully. The students (engineers) on the other hand are not fully satisfied as they are not getting the type of work they like, with the result that there is large scale unemployment, dissatisfaction among employers and also among employees. Therefore, there is a need to develop a curriculum which trains the students to enable them to get employed in the field of their choice, yet meet the requirements of the employers both in terms of numbers and quality of the students. This is what is proposed in this article.

To meet all the above challenges the curriculum must have sufficient flexibility, should be based on employment predictions (preferably for two years later), industry employer participation in formulating and executing the training programs and finally provide opportunity to students to show their interests, talent and get satisfaction. Such a curriculum is suggested below which is likely to overcome some of the draw backs of the present system and meet the aspirations of the students and their employers.

\section{Structure of the Proposed Engineering Curriculum}

It is proposed to admit the students to an institute (with fixed number of disciplines at the time of admission) without assigning the students to any branch. All of them go through the same training which we call it foundation of engineering. The training includes both course (class) work and laboratories for 2 years or 4 semesters.

Each semester would have 5 courses and five laboratory programs. One day is left for students to carry out any unfinished work getting their doubts cleared and for group discussions between the students. In the $1^{\text {st }}$ semester courses and laboratory programs are some sort of bridge courses between what they studied in intermediate and what they are likely to study in engineering. Hence, they take the flavor of physics, chemistry, mathematics, computer programming and programming languages.

In the $2^{\text {nd }}$ semester they are exposed to more of engineering activities like measurements and instrumentation, electrical energy and electrical technology, mechanical tools and systems, strength of materials, analysis of structures and basic electronics. Structure for this semester also may have 6 day week with five courses and five laboratories and 1 day for general activities.

$3^{\text {rd }}$ semester: similar to first two semesters. The topics that may be taught are

1) Thermo dynamics and its applications.

2) Information theory

3) Reliability and its role in engineering

4) Control systems

5) Networks and network analysis.

$4^{\text {th }}$ semester program may be as given below: 
1) Optimization techniques including optimization algorithms

2) Computer and computer applications including CAD

3) Electronics and electronic circuits.

4) Engineering economics

5) Communication skills.

At the end of the $4^{\text {th }}$ semester the students may be asked to choose the discipline. It is time they started testing the various activities that are connected with engineering and also develop some interest in specific activities. Further there would be some indication about the placement position after two years from then.

In $5^{\text {th }}$ semester we propose that the student takes two subjects which form the core subjects for the discipline and two subjects as electives which he can take from the courses offered in the institute, one subject can be a mini project in this semester and also there would be 4 laboratory programs closely connected with the course work. Students may be allowed to replace one of the elective courses by a mini design or development project. The project is generally suggested by the student himself and should be approved by the department and should be carried out under the supervision of a staff member. In this semester, the courses are jointly offered by interested industries and staff of the institute. The content of the courses is also formulated jointly and they can vary from year to year. Some of the mini projects may be suggested by the staff and industries.

$6^{\text {th }}$ term is devoted to give an opportunity to the students to formulate a course (elective) by selecting different units ( 5 units) from different courses available, which may be needed for carrying out his projects effectively. One core course in ones discipline will be taken to give a overall picture of the implications of this course.

Two general electives from any of the courses offered in the institute and one mini project which is likely to be related to the main project he is going to carry out in the final year would form the course structure for this semester.

Final year Project generally is suggested by the student keeping in view, his/her interest, likely place of placement and the feasibility of such a program with the available facilities. The project suggested by the student is to be reviewed by institute and industry and approval may be given based on its feasibility. Further this activity is to be monitored continuously and jointly by the institute and the industry which is likely to have interest in it.

Placement exercise should start only after $7^{\text {th }}$ semester when the project is about to be completed and this ensures continued interest of the student to achieve something of his/her interest and get a suitable placement which gives them work satisfaction.

This type of curriculum can be implemented only if the industry or employing institute comes forward to join hands with institutes in formulating and conducting this program. For the industry it is not an extra effort as these people spend considerable amount of time in selecting the candidates through examinations and interviews. Their project training effort can be channeled through the institutes while the students are still in the institute. Further this would encourage the students to put maximum effort in an area of their interest and show their skills and abilities. Hence, we feel that implementing proposed curriculum is possible once the mind set of corporate organizations changes and they join hands with institutes to train the students and allow them to evolve and reward them.

\section{Benefits of the Proposed Engineering Curriculum}

The following benefits may accrue

1) Most of the students will be able to work in the areas of their own interest and hence, it would lead to work satisfaction for the students.

2) The problem of scarcity of jobs and glut of jobs will be solved to some extent and hence, proper balance of employment would occur.

3) Since, the projects are generally based on groups of students working together, the culture of sharing thoughts would be inculcated among the students.

4) There are many problems to be solved which need knowledge in different disciplines and this program provides a base for initiating the students to address these inter disciplinary tasks.

5) This program also gives an impetus to the students to orient their thinking towards advanced research and development activities.

\section{Conclusions}

In this article we suggested a pattern of curriculum for engineering program in our country. This enables generation of man power that meets the requirements of the industry, employing organizations while providing ample opportunities to the students to exhibit their potential as people with ideas, capable of generating innovation and ability to serve the society and finally serve themselves with career giving them work satisfaction. In this paper, we have suggested that the present curriculum must have sufficient flexibility, which should be based on employment predictions, industry employer participation in formulating and executing the engineering training programs and finally providing opportunity to students to show their interests, talent and get job satisfaction is highlighted.

\section{Bibliography}

1) Bloom, B., Englehart, M. Furst, E., Hill, W., \& Krathwohl, D., Taxonomy of educational objectives: The classification of education goals. Handbook I: Cognitive domain. New York, Toronto: Longmans, Green, 1956.

2) Grayson, D., Collier-Red, B., Pearce, H., \& Shay, S.. A curriculum framework for flexible engineering degrees in South Africa. Paper presented at the Enhancement and 
innovation in Higher Education, Glasgow, UK, pp: 343$352,2013$.

3) Grumet, M, The curriculum: What are the basics and are we teaching them? In J.L. Kinchloe \& S.R. Steinberg, Thirteen questions: Reframing edcuations's conversation. 2nd Edition. New Yrok: Peter Lang, 1995.

4) Shapiro, D.F. Facilitating holistic curiculum development. Assessment \& Evaluation in Higher Education, 28(4), pp: 423-434. 2003.

5) Toohey S, Designing courses for higher education, Society for Research into Higher Education/Open University Press, Buckingham, 1999.

6) Walkington, J. A process for curriculum change in engineering education. European Journal of Engineering Education, 27(2), pp: 133-148, 2002. 